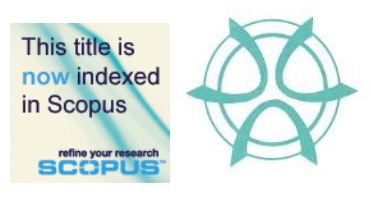

PLANNING MALAYSIA:

Journal of the Malaysian Institute of Planners

VOLUME 16 ISSUE 1 (2018), Page 173 - 182

\title{
UNIVERSAL DESIGN IN URBAN PUBLIC SPACES FOR PEOPLE WITH DISABILITY. CASE STUDY OF TEHRAN, IRAN
}

\author{
Elnaz Esfandfard ${ }^{1}$, Mohammad Hussaini Wahab ${ }^{2} \&$ Rohayah Che Amat $^{3}$ \\ ${ }^{1,2,3}$ UTM Razak School of Engineering and Advanced Technology \\ UNIVERSITI TEKNOLOGI MALAYSIA
}

\begin{abstract}
Urban public spaces play important role in providing good quality of life to the people living in the city. This is in line with the social goal on sustainable development, which the purpose is to attain a higher social equity. According to the World Health Organization (WHO), $15 \%$ of global population are disabled. During the eight-year war between Iran and Iraq, many of the victims in Iran were left disabled. The war left many people injured and this has significantly increased the impairment rate. Amongst the problems faced by people with disability in Tehran are difficulty traveling in the city, lack of public facilities and accessibility to particular facilities such as urban public spaces. This study first sought a definition of urban public spaces and Universal Design, and then finding solution for increasing interaction of people with disability in urban public spaces through Universal Design approach. This research was based on applied theory and qualitative method of field observation was engaged. One of the city district in Tehran was chosen for a case study. Based on the findings, urban design methods and solutions were suggested to increase the interaction and comfort of disabled people in urban public spaces.
\end{abstract}

Keyword: universal design, urban public space, disabled people 
Elnaz Esfandfard, Mohammad Hussaini Wahab \& Rohayah Che Amat

Universal Design in Urban Public Spaces for People with Disability. Case Study of Tehran, Iran

\section{INTRODUCTION}

More than 1 billion people, or $15 \%$ of the world's population, experience some form of disability (WHO, 2011). This group of population continues to increase, partly due to wars in different parts of the world (Azizi, Momeni, \& Taghinia, 2011). During the eight-year war between Iraq and Iran, many of the people in Iran have fallen victims, resulting in disabilities (Eslami \& Mahmoudi, 2016; Imami, 2014). Based on the National Population Survey in 2006, the population with disability in Iran was 2,514,744 people (Segherlou \& Farzin, 2014).

As with normal people, those with disabilities are still required to work and live daily their lives. However, this can be a chore especially in a city which was built and designed for normal people (Ezzati \& Shaghaghi, 2014; Rahnama \& Heydari, 2013). This comes in the forms of facilities which were not built according to standards that are disabled-friendly, hence limiting accessibilities by the disabled.

The urban environment should be able to provide more services to vulnerable groups of the population so that they are not forgotten or marginalised. Properly and suitably designed public spaces could contributes in ensuring equal opportunities to all layers of society and help to increase urban mobility. Thus proper and suitable design should be a requirement in the provision of community facilities (Davarinezhad \& Rahnama, 2015). Physical barriers would limit the use of the public space realm by the disabled, the elderly, people with disabled child, pregnant women, etc. (Yousefi \& Fardi, 2016). Areas important for mobility, such as pedestrian walkway, must be free from barriers that can prevent the disabled from having enjoyable excursions on urban streets (Asadi-Shekari, Moeinaddini, \& Zaly Shah, 2012; Sisiopiku \& Akin, 2003).

By applying Universal Design concept in urban public spaces, people with disability could use the urban area and urban environment similar to other members of the society and they could continue their public life even without any help. Urban public spaces must meet the necessary and important needs of people with disability as part of the urban community. Thus, this study first seeks the definitions of urban public spaces and Universal Design before identifying some of the most important problems of people with disability in urban public spaces that could solve by applying Universal Design concept.

\section{RESEARCH BACKGROUND}

\section{Urban Public Spaces}

People's public life occurs in urban public spaces in a complex set of forms and functions. Accordingly, these spaces must be capable to contain diverse behaviour, uses and activities such as shopping, walking, conversation, using the facilities to entertain, relax or even passing the time as daily activities, and also periodic festivities and events (Jalaladdini \& Oktay, 2012). The urban 
PLANNING MALAYSIA

Journal of the Malaysia Institute of Planners (2018)

environment should be able to provide more services to vulnerable groups of the population to avoid them from being marginalised and forgotten. Public spaces where people regularly meet their friends and conduct their daily activities play a critical role in people's lives (Low, 2000; Mehta, 2013).

Many of the previous studies have focused on the accessibility of specific groups in public spaces, such as women, the poor, specific racial groups, the disabled and the elderly (Mehta, 2013). This is because public spaces contribute significantly in shaping the quality of life of the people. This is akin to the social target of sustainable development, which aim is reaching a greater social equity (Reiter \& Herde, 2011).

\section{Universal Design}

Universal Design is the design of products and environments to be usable by all people, to the greatest extent possible, without the need for adaptation or specialized design (ESLAMI \& MAHMOUDI, 2016). Universal Design is one approach that supports in maintaining social sustainability factors which giving fair distribution of wealth and services within and between generations (i.e. intra and intergenerational equity) as well as the distribution of rights to use environmental services contained within a given ecosystem (Rahim, 2012).

Despite initial perception, Universal Design has proved to be a new source of inspiration for designers in their quests to achieve designs that suits wide range of users. The Universal Design concept is defined as the design of space and applied equipment for most of people with any ability or age, consistent with their needs in the space (Imrie \& Hall, 2001; Segherlou \& Farzin, 2014). In other words, the main aim of Universal Design is not to make people fit to space but to make the space fit to people (Demirkan, 2011; Türk, 2014). The Universal Design concept promotes a shift to more emphasis on user-centred design by following a holistic approach and aiming to accommodate the needs of people with disabilities, including the changes that people experience in the course of life (Ginnerup, 2009).

According to Mustaquim (2015), the pursuit for Universal Design can be traced back to the year 1997 when a group of US designers and design educators from five research organisations developed the Universal Design principles. These principles are as shown in Table 1 below.

Table 1: The seven principles of Universal Design

\begin{tabular}{ll}
\hline Principle & \multicolumn{1}{c}{ Description } \\
\hline Equitable Use & $\begin{array}{l}\text { The design is useful and marketable to people with } \\
\text { diverse abilities. }\end{array}$ \\
Flexibility and Intuitive Use & $\begin{array}{l}\text { The design accommodates a wide range of } \\
\text { individual preferences and abilities }\end{array}$
\end{tabular}


Elnaz Esfandfard, Mohammad Hussaini Wahab \& Rohayah Che Amat

Universal Design in Urban Public Spaces for People with Disability. Case Study of Tehran, Iran

Simple and Intuitive Use

Tolerance for Error

Low physical Effort

Size and space for approach and Use
Use of the design is easy to understand, regardless of the user's experience, knowledge, language skills or current concentration level

The design communicates necessary information effectively to the user, regardless of ambient condition or the user's sensory abilities.

The design minimizes hazards the adverse consequences of accident or unintended actions.

The design can be used efficiently and comfortably and with a minimum of fatigue.

Appropriate size and space is provided for approach, reach, manipulation and use regardless of user's body size, posture or mobility.

Source: Kadir \& Jamaludin (2012)

The concept of Universal Design emerged primarily with people with disability in mind, in which Universal Design helps everyone with support and assistance needs including the elderly, pregnant women, children and people with a temporary illness or injury. Thus the benefits of implementing Universal Design are wide (AusAid, 2013).

According to Rahim (2012) and AusAid (2013), there are 4 categories of design requirement which must be considered in designing accessible environment within and between buildings and in outdoor environment (Table 2).

Table 2: Category of design requirement in Universal Design

\begin{tabular}{ll}
\hline Requirement & \multicolumn{1}{c}{ Component } \\
\hline Sensory & Tactile warnings, guide ways and information \\
\hline Outdoor environment & $\begin{array}{l}\text { Obstructions, signage, street furniture, pathways, kerb, } \\
\text { ramps, pedestrian crossing, alarms }\end{array}$ \\
\hline Horizontal areas & $\begin{array}{l}\text { Doors, entrances areas and lobbies, corridors, handrails and } \\
\text { railings, bridges }\end{array}$ \\
\hline Vertical areas & Ramps, lifts and stairs \\
\hline Source: Rahim (2012) &
\end{tabular}

\section{Disability}

A disable person is someone who is disabled due to organ failure and has difficulty in performing his or her daily routine activities, as well as those suffering from congenital malformations or mental retardation, and diseases and injuries (Hosseini, 2008). Thus, disability includes various physical and mental 
impairments that can hamper or reduce a person's ability to carry out his daily activities (Disabled World, 2017).

According to the WHO (2011), disability is a development issue because of its bidirectional link to poverty; disability may increase the risk of poverty and poverty may increase the risk of disability. An increasing body of research acknowledges that people with disability and their families are more likely to experience economic and social disadvantages than those without disability. In almost every sector of society, people with disabilities, with their physical differences, are to be found. This generates different attitudes in people towards people with disabilities in society, and these diverse attitudes hamper people with disabilities from fulfilling their social needs (Meshur, 2016).

Meanwhile, scholars observe that people with disabilities would experience the built environment in the form of a series of barriers (Yousefi \& Fardi, 2016; Imrie \& Hall, 2001). Disabled people encounter many problems, these vary according to the types of disability they have, in urban spaces and their social surroundings. In the case of disabled pedestrians, movement barriersrelate to their physical-movement characteristics and the lack of both infrastructure and facilities in urban areas (Asadi-Shekari et al., 2012).

\section{METHODOLOGY}

Similar to Shamsuddin, Hassan and Bilyamin (2012), this study employed observation as a means to assess the relationship between the actual practices and the respondent's feedback in the context of the study. In this regard Vali-Asr Street in Tehran, which is the largest street in the capital of Iran, was chosen as the case study area. One zone of the street was studied, which was the ValiAsr Junction. This place represents one of the major nodes in the city centre that have the highest pedestrian volume. ValiAsr Street is one of the famous streets in Tehran which connects the city's south and north sides. This street is considered as one of Tehran's main thoroughfares and commercial centres.

\section{FINDINGS}

The state of sidewalk has a significant impact on the quality of pedestrian environment. Based on observation, the condition of sidewalks along the ValiAsr Street can be rated as average with potholes and cracked paving can be found in some of the areas. These make for uneven walking surface and poses risk of tripping for pedestrians, especially for people with disabilities such as the elderly, wheelchair users and the blind. The sidewalks were paved with non-standard and slippery pavement material after its reconstruction. The use of this material has caused pedestrians to slip especially during wet days.

Besides paving material, the presence of barriers and obstacles also have negative impact on the safety and quality of pedestrian movements. In the study area, many obstructions on the sidewalks and the roadway can be seen. There 
Elnaz Esfandfard, Mohammad Hussaini Wahab \& Rohayah Che Amat

Universal Design in Urban Public Spaces for People with Disability. Case Study of Tehran, Iran

were considerable number of manhole covers on sidewalks that are not at the same level with the pavement, creating bumps for pedestrians. Tactile paving, which can assist the visually impaired finding their way easier, were not used. The absence of tactile paving was also evident at zebra crossings. Only plastic bollards were used at some of the crossings, as temporary barriers, to provide some form of warnings to pedestrians.

Pedestrian crossings at traffic lights were not fitted with audible alarm and crossing timers. With high volume of pedestrians in the area, crossing street may become dangerous to the disabled without the presence of audible alarm and timer.

Signs and directional maps and other way-finding elements of streetscape can help pedestrians to navigate their way easier. In the study area, while the signage were suitable to most pedestrians, they did not meet the needs of the blind due to lack of Braille script on the signage boards. Figure 1 shows the map of Vali-Asr Junction and also the picture which are related to the assessed elements.

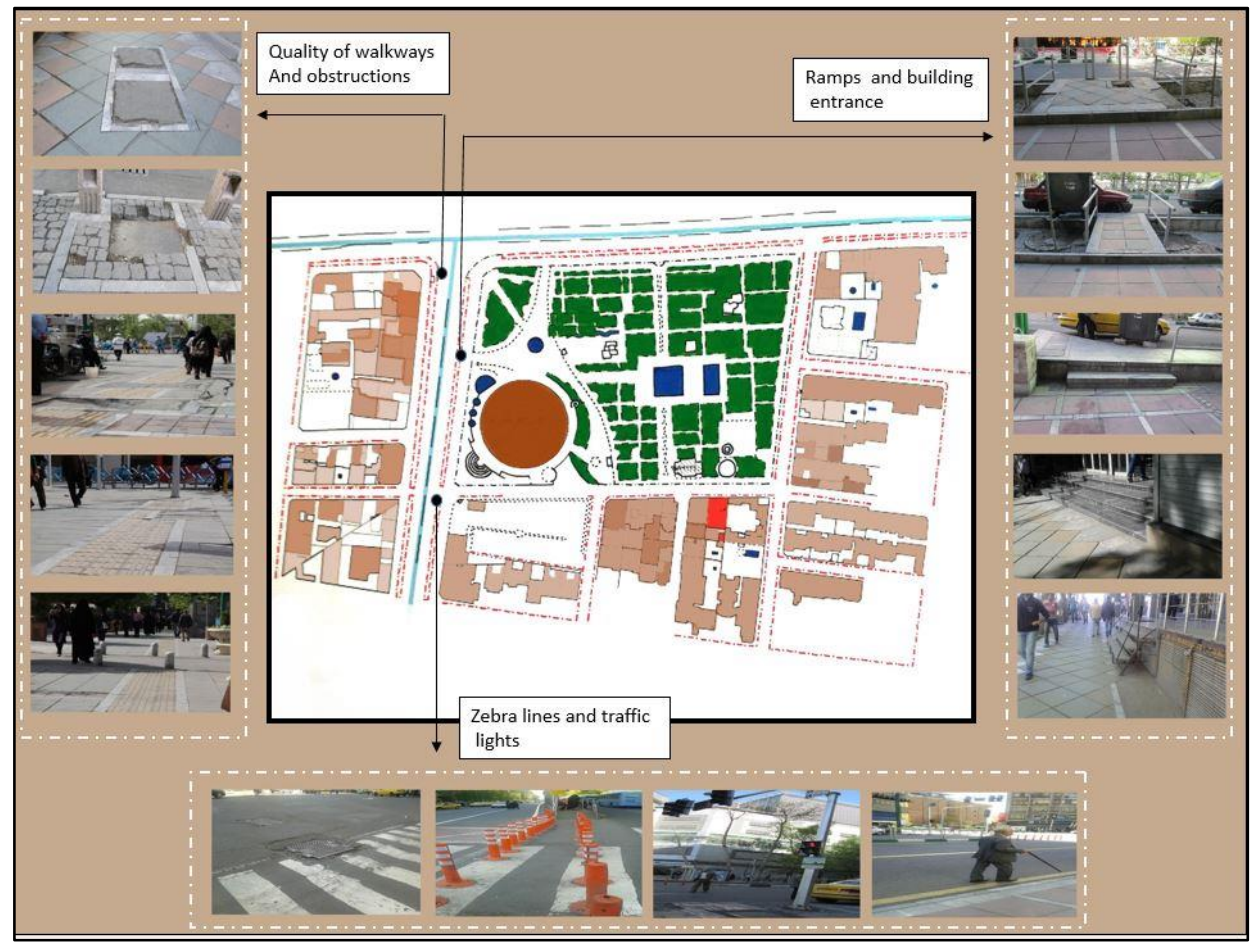

Figure 1: The condition of elements assessed in the study area 
PLANNING MALAYSIA

Journal of the Malaysia Institute of Planners (2018)

\section{DISCUSSION AND RECOMMENDATIONS}

The results indicate that generally the needs of the disabled have been ignored in the design of spaces in Vali-Asr Street. The poor quality of paving and potholes in the roadway created barriers, and making the disabled feel uncomfortable when using the street. The lack of audible alarm at street crossings also makes crossing the street dangerous for people with disabilities, especially the hearing impaired. Therefore, the suggestions to make the street accessible, safe and comfortable for people with disability are outlined below.

- Quality of walkways: Improve quality of sidewalk and roadway paving by using pavement which is resistant to changing climate such as rain, snow and hot summer weather. Good quality paving would make sidewalk surface more resistant to cracks and potholes, allowing for freer and smoother movement by the disabled.

- Obstruction on walkways: Clear sidewalk of any physical barriers that would impede movement of the disabled. Use of tactile paving can also improve the safety of the blinds in using the sidewalk.

- Quality of zebra crossing: Improve quality of zebra crossing by using tactile paving. Zebra crossing must also be clear from obstacles and street island.

- Traffic light: Install audible alarm and timer to provide safer crossing to the disabled. Timer length must consider the movement speed of the disabled to cross the street.

- Street sign: Install signage with Braille script and also with suitable dimension to allow the disabled to easily find their way in the area.

The following diagram shows some of the recommendations based on Universal Design concept which could be applied in Vali-Asr Street. 
Elnaz Esfandfard, Mohammad Hussaini Wahab \& Rohayah Che Amat

Universal Design in Urban Public Spaces for People with Disability. Case Study of Tehran, Iran

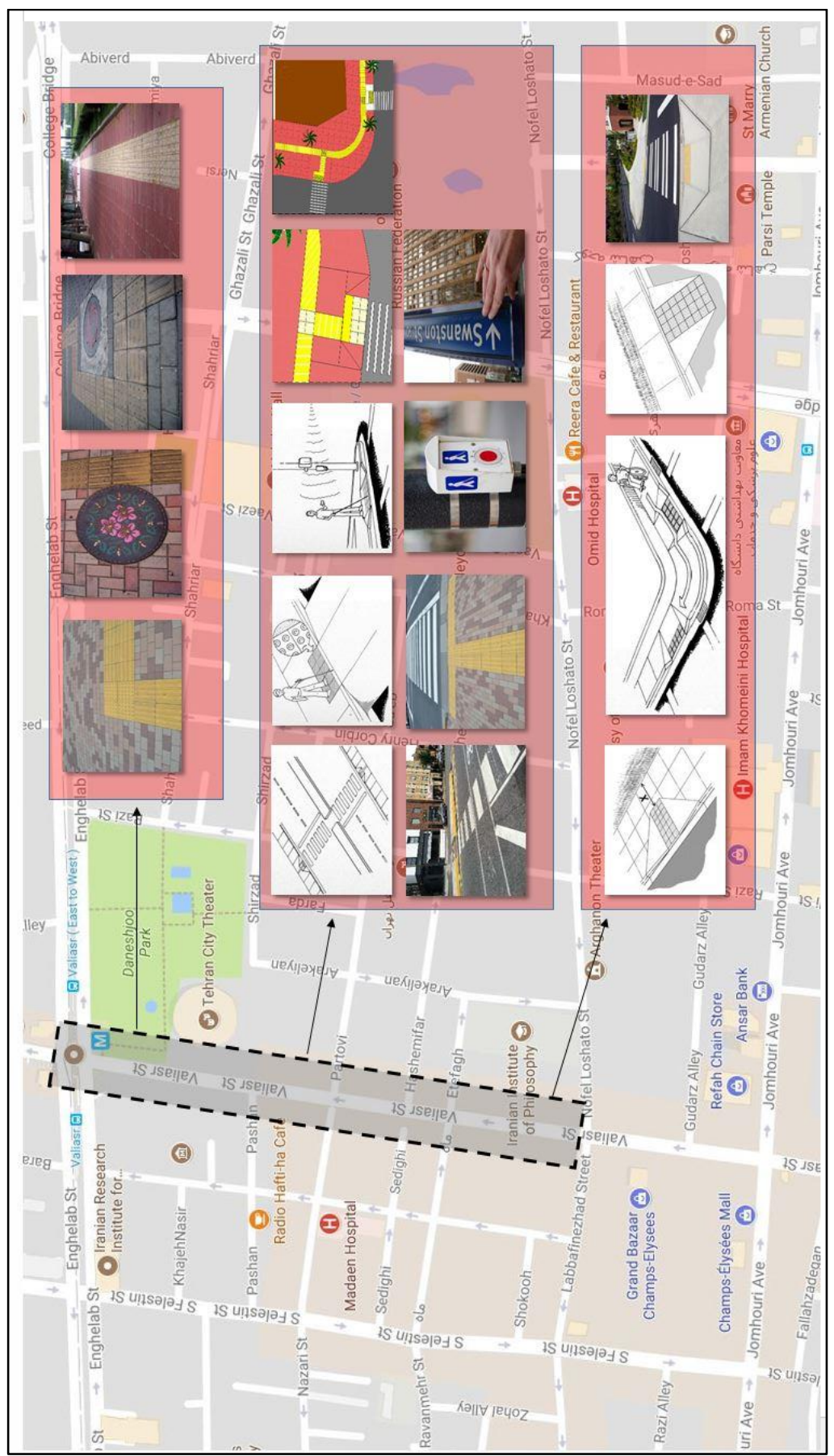

Figure 2: Suggestions for applying Universal Design concept in Vali-Asr Street 


\section{CONCLUSION}

This study assessed the existing condition of public space, i.e. street and pedestrian walkway in ValiAsr Street. The results show that the use of substandard paving material, uneven surface, and lack of measures to enhance safety of pedestrians while crossing the street have hampered the safety and comfort of users of the street, especially the disabled. Thus, design recommendations, based on the Universal Design principles were suggested. The implementation of the proposed design recommendations would help to increase safety and comfort of users, especially the disabled.

\section{REFERENCES}

Asadi-Shekari, Z., Moeinaddini, M., \& Zaly Shah, M. (2012). Disabled pedestrian level of service method for evaluating and promoting inclusive walking facilities on urban streets. Journal of Transportation Engineering, 139(2), 181-192.

AusAid (2013). Accessibility design guide: Universal design principles forAustralia's aid program, Registration Number 13. Retrieved from http://www.ausaid.gov.au/publications

Azizi, H., Momeni, M., \& Taghinia, M. (2011). Quality of life indices assessment for disabled and elderly people: Case study of Tehran.

Davarinezhad, M., \& Rahnama, M. (2015). The assessment of urban furniture for the disabled (Case study: Shiraz City and large park). Journal of Civil Engineering and Urbanism, 1, 16-21.

Demirkan, H. (2011). Tasarım Eğitiminde Herkes için Tasarım Yaklaşımı: Tasarım Deneyimleri ve Uygulamaları. Herkes için Tasarım Müfredatı Geliştirme Çalıştayl, Anadolu Üniversitesi, Eskişehir, 16-17.

Disabled World (2017). Definitions of The Models of Disability. Retrieved from http://www.disabled-world.com/definitions/disability-models.php

Eslami, L., \& Mahmoudi, M. M. (2016). Universal Design and Social Sustainability in the City: The Case Study of Tehran Iran. Studies in health technology and informatics, 229, 263-273.

Ezzati, S., \& Shaghaghi, S. (2014). Regeneration of public urban spaces with point on Disabled People Needs in Tabriz city, Iran. American Journal of Sustainable Cities and Society, 1(3), 314-325.

Ginnerup, S. (2009). Achieving full participation through Universal Design. Strasbourg: Council of Europe Publ.

Hosseini, F. A. (2008). Improving urban furniture and equipment. Shahid Beheshty University of Tehran.

Imami, K. (2014). Value engineering: Creative synergy and the challenges of the third millennium. Tehran: Avaye Ghalam. 
Elnaz Esfandfard, Mohammad Hussaini Wahab \& Rohayah Che Amat

Universal Design in Urban Public Spaces for People with Disability. Case Study of Tehran, Iran

Imrie, R., \& Hall, P. (2001). Inclusive design: Designing and developing accessible environments. Spon Press.

Jalaladdini, S., \& Oktay, D. (2012). Urban public spaces and vitality: A socio-spatial analysis in the streets of Cypriot towns. Procedia - Social and Behavioral Sciences, 35, 664-674.

Kadir, S. A., \& Jamaludin, M. (2012). Applicability of Malaysian standards and universal design in public buildings in Putrajaya. Procedia-Social and Behavioral Sciences, 36, 659-669.

Low, S. (2000). On the plaza: The politics of public space and culture. Austin: University of Texas Press.

Mehta, V. (2013). Evaluating public spaces. Journal of Urban design, 19(1), 53-88.

Meshur, H. F. A. (2016). Evaluation of urban spaces from the perspective of universal design principles: The case of Konya/Turkey. Tema - Journal of Land Use, Mobility and Environment, 9(2), 59-76.

Mustaquim, M. M. (2015). A study of Universal Design in everyday life of elderly adults. Procedia Computer Science, 67, 57-66.

Rahim, A. A. (2012). Universal Design in maintaining social sustainability.

Rahnama, M. R., \& Heydari, A. (2013). North west border cities of Iran and regional development: A case of Kurdistan Province. Journal of Geography and Regional Planning, 6(5), 184-192.

Reiter, S., \& Herde, A. D. (2011). Qualitative and quantitative criteria for comfortable urban public spaces. 2nd International Conference on Building Physics. Antwerp, Belgium.

Segherlou, E. N., \& Farzin, A. A. (2014). Comparative study of urban public spaces based on the need of disabled with universal design approach (Case study: District 6 of Tehran Municipality).

Shamsuddin, S., Hassan, N. R. A., \& Bilyamin, S. F. I. (2012). Walkable environment in increasing the liveability of a city. Procedia-Social and Behavioral Sciences, 50, 167-178.

Sisiopiku, V. P., \& Akin, D. (2003). Pedestrian behaviors at and perceptions towards various pedestrian facilities: an examination based on observation and survey data. Transportation Research Part F: Traffic Psychology and Behaviour, 6(4), 249-274.

Türk, Y. A. (2014). Planning-Design Training and Universal Design. Procedia-Social and Behavioral Sciences, 141, 1019-1024.

WHO. (2011). Concept note: World report on disability and rehabilitation. Geneva: World Health Organization.

Yousefi, M., \& Fardi, R. (2016). Physical responding of the urban public space to citizens' rights. Mediterranean Journal of Social Sciences, 7(3), 167-172. 